\title{
CONFESSIONS OF A MOOCER: AN AUTOETHNOGRAPHIC INQUIRY ON ONLINE DISTANCE EDUCATION
}

\author{
Romualdo Atibagos MABUAN \\ Department of English and Literature \\ Lyceum of the Philippines University \\ Manila, Philippines
}

\begin{abstract}
Massive Open Online Courses (MOOCs) are dramatically restructuring, reshaping, and redefining the vast landscape of teaching and learning across the globe. With MOOCs' ubiquity, openness, and accessibility, they have become a new platform for teacher professional development. Utilizing a co-constructed narrative inquiry, this paper aimed to examine aspects of our memories, perspectives, and experiences in successfully completing Teach English Now! a 150-hour online Teaching English to Speakers of Other Languages (TESOL) Certificate Course from Arizona State University, United States of America via Coursera (www.coursera.org) as the MOOC platform. Acting as reflective practitioners and as teachers-as-researchers, we unpacked how we traversed the massive information superhighway in our quest for teacher professional development, what it was like to be an online learner, how we saw our role, why we believe what we believe about MOOCs' potential, and how we think all of these affect our decisions and practices in our classrooms and contexts. Data from our individual journals, individual reflections, and peer discussion revealed how MOOCs' features such as 'openness' and 'flexibility' as afforded by ubiquitous technology, sound course design, and strong learning community support have influenced us personally, socially, and professionally, making it a practical platform for teacher professional advancement particularly in developing countries such as the Philippines. Andragogical and pedagogical implications are provided in the light of our MOOC experience.
\end{abstract}

Keywords: Connectivism, cyberlearning, massive open online courses (MOOCs), online distance education, teacher professional development.

\section{INTRODUCTION}

Since the inception of CCK08: Connectivism and Connected Knowledge, a massive open online course (MOOC) that was designed and facilitated by George Siemens and Stephen Downes in 2008, taken by 25 students enrolled at the University of Manitoba and participated in at the same time by over 2200 students from the different parts of the world at no cost and without earning any credit (Educause, 2011; Decker, 2014; Lowe, 2014), the 'digital revolution' in education (Brabon, 2014, p.1) was born. Since then, global education leaders, policy makers, field practitioners, and researchers have turned their gaze to the potentials of MOOCs in reimagining how knowledge can be communicated via this modern platform and in investigating whether MOOCs provide sound instructional design leading to quality outcomes and experiences for the students (Hayes, 2015). Regarded as the new era of learning (Soylev, 2017), MOOC has become 2012's buzzword in higher education (Chen, 2014), making 2012 the "year of the 
MOOCs" (Pappano, 2012). David Willetts, former U.K. Universities and Science Minister once considered MOOCs as "the opportunity to widen access to our world-class universities and to meet the global demand for higher education" (Wintrup, Wakefield, \& Davis, 2015, p. 6). Billington and Fromueller (2013) and Dyer (2014) stated in Israel (2015) that MOOC is a catalytic innovation that is set to revolutionize the landscape of higher education.

MOOC stands for Massive Open Online Course, which is a term coined by Dave Cormier after Siemens and Downes' CCK08 MOOC; however, Siemens and Downes credit the term to David Wiley and Alec Couros who created their own wiki-based free online courses in 2007 (Decker, 2014). Massive pertains to the potential of attracting thousands of enrollees from different parts of the world such as the case in 2011, when a MOOC on Artificial Intelligence developed by Sebastian Thrun who was a professor at Stanford University, was taken by approximately 160,000 students from around the globe with 28,000 students who successfully completed the course. Open means that anyone from anywhere in the world, regardless of educational background, socioeconomic status, gender, age, and color, can enroll in a MOOC via the Internet. Liyanagunawardena et al. (2013) indicated that the word Open suggests that MOOC participation does not necessarily have requirements such as academic background, tuition fees, and course completion. Others suggest that the term Open should refer to Open Access, which means that the content of a MOOC is not only free and available to everyone, but is under Creative Commons License allowing anyone to download, save, reuse, remix, retain, and redistribute content to suit his or her purpose and context with proper acknowledgement of the developer (Decker, 2014). Yuan and Powell (2013 in Philippine Institute for Development Studies, 2015) wrote, "The development of MOOCs is rooted within the ideals of openness in education, that knowledge should be shared freely, and the desire to learn should be met without demographic, economic, and geographical constraints." Online refers to the mode of content delivery, which is accessed by the learner via the Internet using electronic gadgets such as desktop computer, laptop, tablet, phablet, and cellular phone. Course entails the format of how a certain course operates with phases such as enrollment, start and end dates, course content, assessment and evaluation.

The MOOC movement in educational landscape was picked up by various institutions and they started establishing MOOC platforms in collaboration with various field experts and organizations. Some of the most notable MOOC providers in the world include the following: Udacity (www.udacity.com), founded in June 2011 by Sebastian Thrun, David Stavens, and Mike Sokolsky and established in February 2012; Coursera (www.coursera.org), founded by Andrew $\mathrm{Ng}$ and Daphne Koller and launched in April 2012; edX (www.edX.org), created by scientists from Harvard University and Massachusetts Institute of Technology (MIT) and opened in May 2012; Canvas Network (www.canvas.net), launched in November 2012 by Instructure which was founded by Brian Whitmer and Devlin Daley in 2008; Open2Study (www.open2study.com), launched in April 2013 by Open Universities Australia; and Iversity (www.iversity.org), created by Jonas Liepmann and Hannes Klöpper and founded in October 2013.

MOOCs gained both appraisals and criticisms. Opinions about MOOCs are divided about their value and importance. MOOCs are seen as "significant catalysts" in education (Bayne \& Ross, 2014), as "an innovation with great potential to widen participation and promote lifelong learning" (QAA, 2014), and as a "recent stage in open education" (Creelman, Ehlers, \& Ossiannilsson, 2014). On the other hand, MOOCs are viewed as "disruptive technology" (Christensen, 2010) possessing the "characteristic of bringing disruptive education" (Zancanaro, Nunes, and Domingues, 2017), as merely a "marketing exercise" (Conole, 2013), and as a "lousy product" (Thrun, 2013). And in places like 
Harvard, several liberal arts professors have been protesting "the rush to embrace MOOCs, which they worry will undermine the personal, intellectual connection inherent to a liberal arts education" (Carr, 2013, p. 2 in Johnson, 2013). Nevertheless, Creelman et al. (2014) emphasize that 'MOOCs present the possibility of new approaches to education,' and Wintrup et al. (2015) suggest three key areas for further research on MOOCs: education enhancement focusing on curriculum development, higher education and marketing, research, and policymaking.

M00Cs for Teacher Professional Development

The egression and utilization of MOOCs for teacher professional development (henceforth, TPD) remains uncommon, as recent studies on MOOCs primarily focuses on MOOCs' nature in providing connectivity of learning (Mercado-Varela, Beltran, Perez, Vazquez, \& Ramirez-Montoya, 2017), evaluation of various platforms used in the delivery of MOOCs (Zancanaro, Nunes, \& Domingues, 2017), and evaluation of different types of MOOCs (Kocdar, Okur, \& Bozkurt, 2017), inter alia. Research on MOOCs primarily deals with their effects for higher education and lifelong learning, with little attention given to the intersection of MOOCs and TPD. However, studies on MOOCs for TPD is on the threshold of gaining momentum (Jobe, Ostlund, \& Svensson, 2014). While TPD is considered a developing field of research, Evans (2002) comments that the concept of TPD still lacks a clear definition. He then defines TPD focusing on "professional development as a process, where a teacher performs an activity to achieve attitudinal and functional development." TPD can foster improvements in teaching (Kennedy, 2016). Kennedy (1998) categorized research on TPD into four foci: (1) generic teaching principles, (2) subject-specific teaching practices, (3) curriculum and pedagogy, and (4) how students learn. Major research on TPD focused on TPD per se (e.g., Borman, Gamoran, \& Bowdon, 2008; Penuel, Gallagher, \& Moorthy, 2011), evidence of student achievement (e.g., Roschelle et al., 2010), motivation for learning (e.g., Roth et al., 2011), impact on student performance (e.g., Heller, Dahler, Wong, Shinohara, \& Miratrix, 2012), and TPD program design (e.g., Sher \& O'Reilly, 2009; Opfer \& Pedder, 2011).

Conducting TPD is often costly, as it requires the use of resources from both the funding organization and the teacher participant. For instance, Odden, Archibald, Fermanich, and Gallagher (2002) created a framework that discusses the elements involved in TPD and their corresponding costs. These elements include the following: (1) teacher time, (2) training and coaching, (3) administration, (4) materials, equipment, and facilities, (5) travel and transportation, and (6) university tuition and conference fees.

With the increasing costs of and high demand for TPD, the most practical option is to use the concept of MOOC. Through MOOCs, teachers can access online courses free at their own pace and space. MOOCs for TPD are now becoming popular. For example, Coursera, in collaboration with its course providers, recently launched courses specifically for TPD (Pope, 2013). In fact, Coursera now contains a search parameter like "Teacher Professional Development", which currently has 1,164 courses available to interested MOOC participants. This development suggests that MOOC providers acknowledge the trend that the number of MOOC participants who have degrees is increasing, and that they enrol in MOOCs to advance their learning. This was observed by Emmanuel (2013) in his study, which indicated that $83 \%$ of MOOC participants were already holding two- or four-year post-secondary degrees. Hence, MOOCs now are seen to be "moving from offering only traditional learning to even offering career development (lifelong learning) and blended learning opportunities" (Emmanuel, 2013). One study that affirms this observation was conducted by Mackness, Waite, Roberts, and Lovegrove's (2013), which showed that "small task-oriented MOOCs can effectively support professional development of open academic practice." However, while MOOCs for teacher professional 
development are increasingly gaining momentum, there is little account about their effectiveness to the teacher participants in various contexts. "In general, the body of research studying the use of MOOCs for teacher professional development is scarce" (Jobe, Ostlund, \& Svensson, 2014). It is this gap that this paper intends to address.

\section{Arizona State University's Teach English Now! A MO0C for TPD}

This paper explores our experiences and viewpoints upon successfully completing Teach English Now! - a teacher professional development program offered by Arizona State University (ASU) via Coursera. Located in Tempe, Arizona, United States of America, ASU is a top 100 school globally and is recognized for its outstanding programs and innovations. ASU is ranked 1 'Innovative University in the U.S.' and ranked 1 'Producer of Fullbright Scholars' by the U.S. News and World Report. Coursera is the world's biggest MOOC platform with 149 university partners, over 2,000 courses, more than 180 specializations, 4 degrees, and over 25 million learners. Teach English Now! is an online 150-hour TESOL or Teaching to Speakers of Other Languages Certificate Program consisting of a series of eight courses that can be completed on a self-paced mode from 16 weeks to 1 year. This course meets all standards outlined by the TESOL International Association - the world's authority for TESOL for over 50 years now.

The Teach English Now! TESOL Certificate Courses include the following: (1) Foundational Principles, (2) Theories of Second Language Acquisition, (3) Lesson Design and Assessment, (4) Second Language Reading, Writing, and Grammar, (5) Second Language Listening, Speaking, and Pronunciation, (6) Technology-Enriched Teaching, (7) Capstone 1, and (8) Capstone 2. The estimated cost of the TESOL Certificate is \$392.00. We started to take Teach English Now! last April 2016 and we successfully completed the eight courses. We graduated last December 2016 and received our TESOL Certificate from ASU.

\section{Research Questions}

This paper shows our experience-based testimonies about our successful completion of ASU's 150-hour Teach English Now! TESOL Certificate Course and how it has shaped our professional development as English language educators. Specifically, we aim to answer the following questions:

$>$ What are the features of Teach English Now! that make it an effective online course for teacher professional development?

$>$ How do we reflect upon our teacher professional development based on our Teach English Now! experience?

\section{METHOD}

This study utilized an autoethnographic inquiry to reveal our personal experiences in participating in and completing Teach English Now! as a form of our teacher professional development. "Autoethnography is an approach to research and writing that seeks to describe and systematically analyze (graphy) personal experience (auto) in order to understand cultural experience (ethno)" (Ellis, 2004; Holman Jones, 2005). Autoethnography can take in many forms: layered accounts (Charmaz, 1983), reflexive ethnographies (Ellis, 2004), narrative ethnography (Tedlock, 1991), co-constructed narratives (Vande Berg \& Trujillo, 2008), interactive interviews (Ellis, Kiesinger, \& Tillmann-Healy, 1997), reflexive dyadic interviews (Ellis, 2004), personal narratives (Tillmann, 2009), indigenous/native ethnography (Denzin, Lincoln, \& Smith, 2008), and community ethnography (Toyosaki, Pensoneau-Conway, Wendt, \& Leathers, 2009). Our 
autoethnographic inquiry aligns with Stenhouse's (1975) 'teacher-as-researcher' and Schon's (1987a) 'reflective practitioner' concepts.

Data

We used co-constructive narratives (Vande Berg \& Trujillo, 2008) to draw upon our experiences in successfully completing Teach English Now! We analyzed our personal journals, chat messages, MOOC discussion forum posts, MOOC peer feedback, ASU expert comments, and dyadic discussion from April to December 2016. After our individual analysis of our experience, we gathered and reflected upon our eight-month MOOC journey. Because we intend to make sense and draw meaning from our experience, the narrative inquiry seems appropriate as it "captures personal and human dimensions of experience over time, and takes account of the relationship between individual experience and cultural context" (Clandinin \& Connelly, 2000). As natural storytelling organisms, humans lead storied lives, which educational research can capture through narratives. The narrative research, therefore, is "the study of the ways humans experiences the world" (Connelly \& Clandinin, 1990). In narratives, we see "the story in the study, the tale in the theory, the parable in the principle, and the drama in the life" (Clifford \& Marcus, 1986; Suleiman, 1986; Turner \& Bruner, 1986; Rosaldo, 1989; Bordo, 1990).

\section{RESULTS AND DISCUSSION}

\section{Navigating ASU's Teach English Now! via Coursera MOOC Platform}

After searching for ways to advance our knowledge and skills in English language teaching, we came across the concept of MOOCs by navigating through the Internet. We have learned about various MOOC platforms such as edX, Coursera, and Udacity, and searched for possible courses that would fit our interest and schedule. We were full-time university instructors and heavy workloads and expensive training costs would usually prevent us from taking leave of absence to attend teacher seminar-workshops and conferences for professional development. We were excited to discover that there were several teacher specialization courses offered by top universities across the globe that we could take via MOOC platforms. After comparing course offerings and syllabi, we finally decided to enroll in Arizona State University's Teach English Now! via Coursera.

Teach English Now! consisted of eight courses amounting to \$49 each. Because we lack financial resources, we decided to avail of Coursera's Financial Aid Program. The 'audit course' option was possible with free access to the courses; however, there would be no certificate given upon completion of the course. We needed to have certificates for submission to our university's promotional program. In applying for Coursera's Financial Aid Program, we needed to answer the following questions for evaluation of the scholarship grant committee. Application for financial aid was required for each of the eight courses. The instructions read like this:

If the financial aid is the right option for you, please proceed by filling out this application:

$>$ What is your annual income in USD?

$>$ Which country are you located in?

$>$ Please describe your financial need and explain the specific circumstances that motivate your request for financial aid. (50-300 words)

$>$ Please tell us why you are taking this course. What is your interest in this field? How would a Course Certificate be valuable to you? (50-300 words) 
$>\quad$ When participating in this course, how do you intend to demonstrate academic integrity and contribute to the course's community? (50-300 words)

We received the financial aid notification from Coursera via email within the day of application. However, at present, it would take approximately 15 days to receive the notification due to bulk applications from several course takers around the world. As soon as we received the scholarship grant from Coursera, we started taking the first of the eight courses of Teach English Now! Each course required a separate application for financial aid. We applied for financial aid for all the Teach English Now! courses, and all of them were granted by Coursera; hence, we did not spend any amount in finishing the eight courses.

MOoc-ing, Learning, Collaborating

We started our online teacher professional development as Teach English Now! participants on April 1, 2016. The eight courses were divided into two specializations: TESOL Certificate, Part 1: Teach English Now! and TESOL Certificate, Part 2: Teach English Now! Part 1 consisted of the following four courses: Teach English Now! Foundational Principles, Teach English Now! Theories of Second Language Acquisition, Teach English Now! Lesson Design and Assessment, and Teach English Now! Capstone Project 1. Part 2 had the following four courses: Teach English Now! Second Language Reading, Writing, and Grammar, Teach English Now! Second Language Listening, Speaking, and Pronunciation, Teach English Now! Technology Enriched Teaching, and Teach English Now! Capstone Project 2.

In Teach English Now! Foundational Principle, we learned about foundational principles on concepts such as motivation, risk taking, and balancing the teacher profession by identifying, summarizing, and evaluating seven basic language-learning paradigms through various insightful metaphors and engaging stories. In Teach English Now! Theories of Second Language Acquisition, we learned about different second or foreign language acquisition theories as well as varied approaches and practices in the teaching and assessment of macro skills such as listening, speaking, and pronunciation, through a presentation of historical approach of teaching practices of different teachers through the years. In Teach English Now! Lesson Design and Assessment, we learned about how to design coherent and effective lesson plans based on several considerations such as formulation of learning objectives, identification of appropriate methods, gathering of relevant materials, organization of learning activities, and assessment and evaluation of student learning outcomes. The course also taught us to identify and prepare teaching materials by carefully analyzing, adapting, and creating our own teacher professional resources.

Teach English Now! Second Language Reading, Writing, and Grammar presents to us information on reading and writing courses, and the integration of grammar within those courses. It took us through a series of fairy tales and fables to examine basic reading and writing strategies. Teach English Now! Second Language Listening, Speaking, and Pronunciation introduced us to the aspects of listening and speaking that are challenging for students and teachers. We also learned about basic strategies that can help ease the acquisition and instruction of listening and speaking. Teach English Now! Technology Enriched Teaching presented us some key concepts on effective integration of technology into our teaching, without overshadowing language learning. We were also introduced to trends in educational technology, as well as strategies on how to adapt, apply, and implement these trends in our own classroom contexts.

Teach English Now! Capstones 1 and 2 were online practicum where we demonstrated our teaching skills, as we built on our completed tasks from the previous courses to deliver lesson 
plans, observe teaching demonstrations from ASU's master teachers, and create a professional teaching portfolio, which served as the final course requirement. The portfolio was a compilation of all the outputs from the eight courses such as teaching philosophy, teacher tip, lesson plans, and micro teaching videos. The capstone for specialization 1 was peer reviewed, while the capstone for specialization 2 was expert reviewed. We prepared 10 hours of lesson plan content and we recorded ourselves instructing for a portion of each of the lesson plans in a micro-lesson format. We recorded 10 videos that were 6-10 minutes long and uploaded full lesson plans. Our peers from the different parts of the world watched our micro teaching videos, read our lesson plans, and provided peer feedback. We also had six hours of observation of full lesson plan videos of ASU master teachers. We received individual certificates for each of the eight courses successfully completed and two additional certificates indicating completion of the specialization courses. After we successfully completed Capstone 2, we received Arizona State University's TESOL Certificate with a certificate number and signed by ASU's Office of the University Provost and the Lead Course Instructor. ASU also provided a permanent verifiable web link for the certificate. Below are samples of the certificates we received from ASU and Coursera.

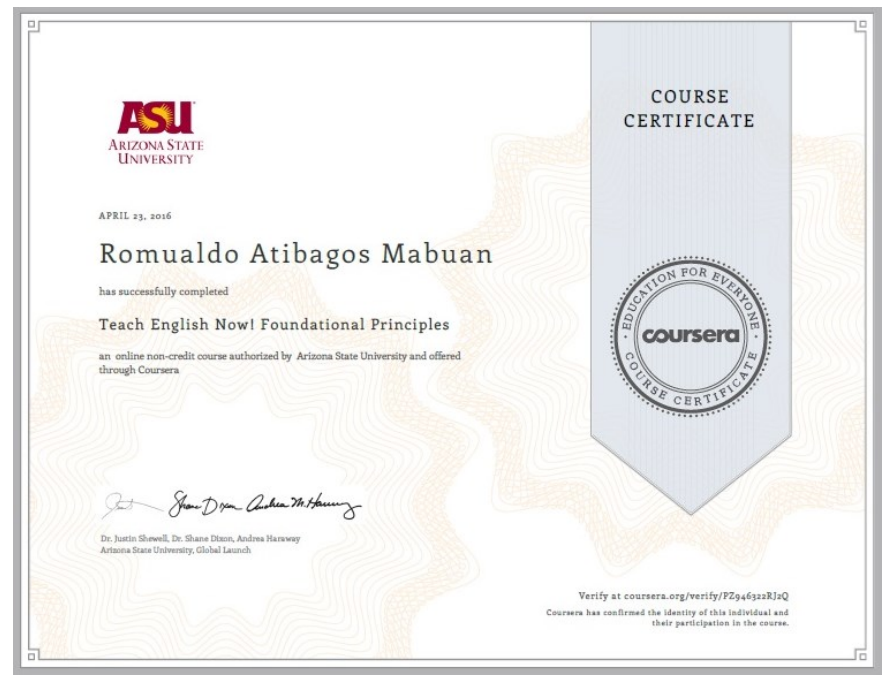

Figure 1. ASU-Coursera Certificate for Individual Courses

(Shareable and verifiable link: coursera.org/verify/PZ946322RJ2Q)

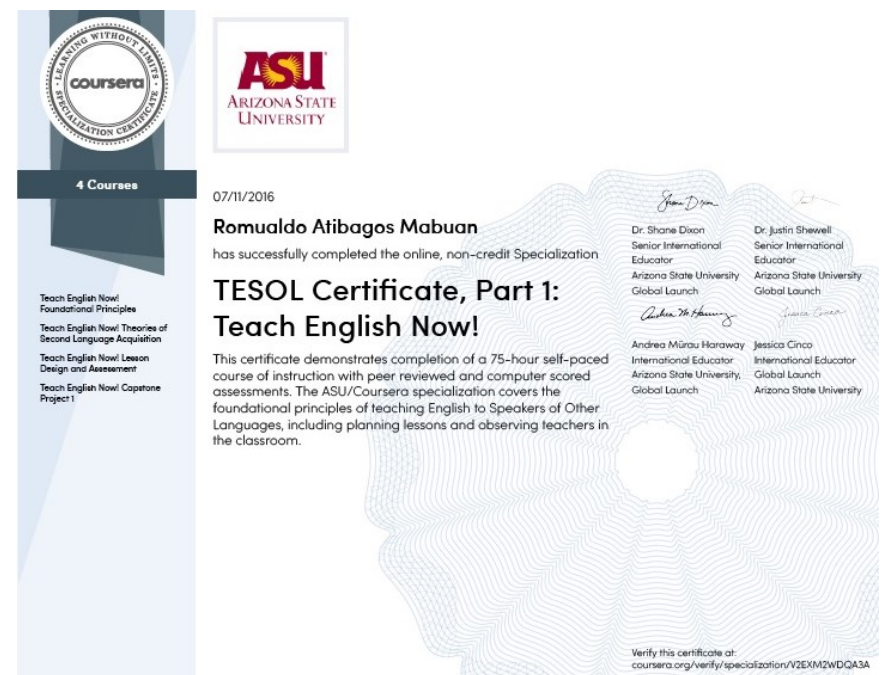

Figure 2. ASU-Coursera Certificate for Specialization Courses (Shareable and verifiable link: coursera.org/verify/specialization/V2EXM2WDQA3A) 


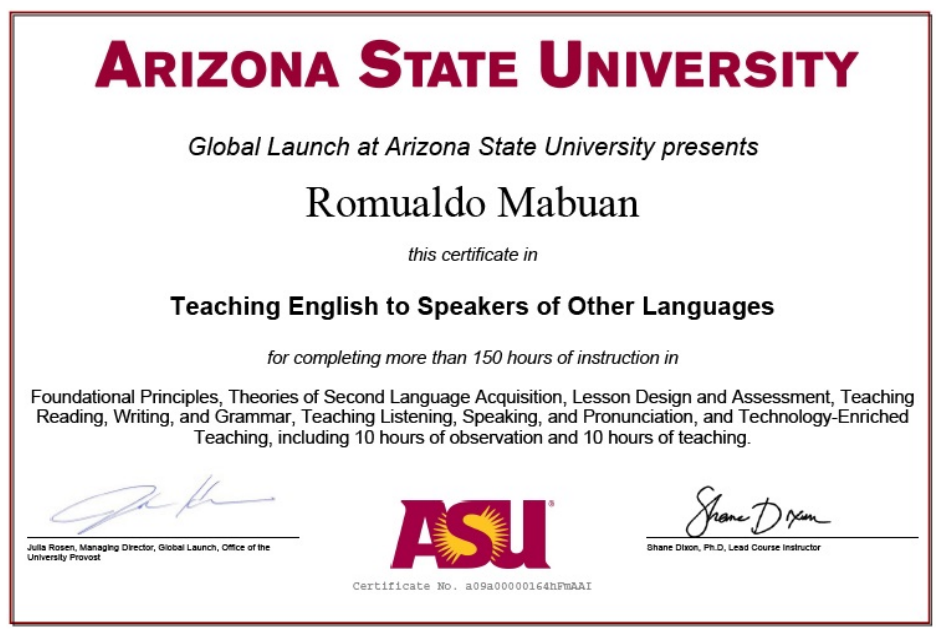

Figure 3. ASU 150-Hour TESOL Certificate

(Verifiable link: https://global-

launch.secure.force.com/certificates/SCOM_MoocCertificate?Id=a09a00000164hFm)

Our ASU-Coursera eight-month journey for teacher professional development was not a walk in the park. We had several simultaneous roles: a full-time classroom instructor with 30 hours of teaching load weekly, a part-time graduate school student taking a doctorate degree in Applied Linguistics, and a MOOC learner. However, despite our hectic schedule, we managed to stay focused on the MOOC by having a strong time management system, self-discipline, and peer collaboration. We engaged everyday via face-to-face discussions, online chats, text messages, and phone calls about our MOOC tasks, consulting with each other and sharing ideas about how we understood certain concepts and how we performed in the online quizzes, peer feedback, expert feedback, online discussion forums, micro teaching demonstrations, and weekly assignments. We had a very challenging time, but we were happy and satisfied that we were learning tremendously every day. After analyzing our journal entries, chat messages, and online discussion posts, we have identified important points that we believe had helped us successfully complete ASU's TESOL Certificate Course. These include the following: (1) comprehensive course design, (2) avant-garde teaching approaches of the MOOC instructors, and (3) engaging and supportive learning community.

ASU's 150-Hour TESOL Certificate Course follows TESOL International Association's standards for short-term TEFL/TESL certificate programs (TESOL.org, 2015), which include organization and program management standards, curriculum and instructor standards, and candidate standards. Following TESOL's organization and program management standards, we observed that the ASU TESOL Course adhered to the following standards: English was used as a medium of instruction, there were clear goals and varied instructional methodologies, there was a formal plan for revision and review, and there were formative and summative assessments. With curriculum and instructor standards, we observed that the curriculum observed prescriptiveness and flexibility of the lessons for local contexts, as well as there were opportunities to demonstrate our best practices. As regards candidate standards, we observed that the following domains were addressed: language, culture, instruction, assessment, and professionalism. We learned about the structure and components of language such as phonology, morphology, syntax, and semantics; the role of language in the society; and the importance of English in the world today. We also learned about the theories of first and second language acquisition, as well as how people learn language in a variety of 
contexts. Furthermore, we learned about planning instruction such as skills integration, implementing instruction such as the inclusion of activities for meaningful and authentic use of language, and using instructional resources such as selection and adaptation of appropriate print and virtual materials. With these, we were assured that the course that we were taking adhered to the global standards, and that we were getting good and quality education that was worth our time, energy, and effort. This finding delineates Chugh, Ledger, and Shields' (2017) claim that sound curriculum design is essential to a successful distance education, which should reflect educational principles, represent elements of engagement and pedagogy, and meet institutional and industry requirements through its triadic features consisting of pedagogy, technology, and community.

Another feature of the course that had captivated us was the use of avant-garde approaches to teaching by ASU TESOL experts, who did not resort to talking-head lecture-style format of teaching. Despite having heavy workloads, we were excited to learn from engaging lecture videos, which employed creative and thematic techniques. Consequently, the course ranked highest in terms of completion rates and student rankings. Some of the learners commented that the course was 'excellent', 'marvelous', and 'amazing'. Other learners noted that 'the course was presented well...the team put together an effective presentation of important techniques for teaching language....and the material was clear, thorough, and important (https://www.coursera.org/learn/english-principles\#ratings). Our journal entry dated $12 / 19 / 2016$ echoes this observation: "Finally, I'm done! It was a challenging yet worthwhile online learning experience. Kudos to the Teach English Now! Team especially to Dr. Shane Dixon for a very engaging and innovative approach to online teaching. Definitely one of the best and most memorable learning experiences for me!" In fact, because of the course's engaging, entertaining, and informative approach, of over 1,800 courses on Coursera, it won the 'Learners First Award' during Coursera's First Annual Outstanding Educator Awards in the Partners Conference in 2016 (http://coursera.tumblr.com/post/142019252717/congratulations-to-the-winners-ofcourseras-first). ASU's Teach English Now! Team comprised of Dr. Shane Dixon, Dr. Justin Shewell, Andrea Haraway, and Jessico Cinco was recognized because of their approaches that are 'remarkably innovative, transformative, or beloved by learners' in 'delivering uniquely engaging and high-quality experience' for the learners. This finding underscores what Mercado-Varela et al. (2017) posited that the facilitators' high digital and pedagogical competence facilitate successful learning connections in a massive course.

Finally, one of the significant highlights of our online TPD was the engaging and meaningful collaboration with over 100,000 learners from over 170 countries who were also taking the course. We had weekly discussion forums where we could post our comments and concerns, respond to queries, and communicate with our classmates and instructors. In addition, as part of the course assessment, all of our micro teaching video demonstrations and full lesson plans were reviewed by our peers who provided valuable feedback and insights about our outputs using rubrics provided by ASU. Likewise, we also performed the same peer feedback assessment, which taught us how to evaluate our peers' outputs and provide suggestions so that they could improve their work. An instance of a motivating and affirmative feedback by a MOOC peer was given 12/07/2016: "Great lesson plans and videos! I like that you applied a lot of techniques that we learned in the courses. You included a lot of good resources! Your teacher talk in the videos is good and you're very enthusiastic!" We also learned how to produce quality outputs based on ASU expert comments, who evaluated our work to ensure that we adhered to the standards set by the course. For instance, an expert feedback dated $11 / 28 / 2016$ stated: "...I don't see any reason to just pass someone so that they can fail 
outside of the class. As a certified teacher in the State of Arizona, and an expert international Educator at ASU, I know what it takes to create a hire-worthy portfolio having created one for myself..." These peer and expert feedback afforded us impetus to continue our MOOC journey; also, they encouraged and challenged us to perform at our best, which prompted us to reflect on our performance and practice. The MOOC acted as a virtual community of practice that allowed individuals to collaborate and learn with one another. This finding embodies the significant role of e-mentoring in a knowledgesharing environment, which can lead to transformative learning among participants (Tanis \& Barker, 2017) through online dialogs, forums, and feedback.

MOOC-ing, Refracting, Reflecting

Our eight-month MOOC journey has reshaped the way we learn and teach. We realized that online education could be as engaging, effective, and meaningful as offline/face-toface education. Our experience with ASU-Coursera's Teach English Now! has taught us that with the right blend of course design, virtual instructors' approaches, and participants' motivation to learn and collaborate, the online TPD could be personally, socially, and professionally rewarding. We obtained invaluable ideas, insights, and perspectives that are now guiding our pedagogical practice. Our chat message dated $12 / 23 / 2016$ affirmed this: "Ito na ang best Christmas gift. Natuto tayo ng marami at libre pa! Di ko inexpect na sobrang fruitful pala ng MOOC. Dami kong kelangan idagdag at baguhin sa approach ko sa pagtuturo..." [This is the best Christmas gift ever. We learned a lot and it was free! I didn't expect that MOOC could be so fruitful. I have a lot to improve and change in my teaching approach..."]. Personally, we have felt fulfilled and happy that we were able to accomplish something that we could consider a lifetime achievement. We have broken barriers to TPD despite our limited resources. We were able to improve ourselves through diligence, fortitude, and willingness to learn. Socially, we have felt connected and engaged as we were able to communicate and collaborate continuously during and after the completion of the course with our global peers and instructors via the MOOC's online discussion forums, Teach English Now! LinkedIn community (https://www.linkedin.com/groups/8572608/profile), and Teach English Now! official Facebook page (https://web.facebook.com/teachenglishnowMOOC/ ?ref=br_rs). Professionally, we have become more confident as English language educators, as we were able to validate our own pedagogical practice through the help of our peers and instructors who provided us useful and practical suggestions to better our craft. We have also gained knowledge and developed our skills through open educational resources (OERs) and practical tasks. We have felt equipped that we were able to understand the theoretical underpinnings of our own classroom practices guided by the teaching and learning principles discussed in the MOOC. We believe that our MOOC journey is not only a learning experience; it is a transformative event in our personal, social, and professional lives.

\section{Connecting the Dots}

Our MOOC experience is a living testimony and contribution to the "relatively novel and uncharted" field of online teacher professional development (OTPD) (Jobe, Ostlund, \& Svensson, 2014). As opposed to previous research findings that suggest that several TPD programs lack quality as they offered "fragmented, intellectually superficial" seminars (Borko, 2004, p.3), our MOOC experience proves otherwise. ASU's Teach English Now! embodies an OTPD that enables improvement of the different aspects of its learners (Whitehouse, Breit, McCloskey, Ketelhut, \& Dede, 2006): "subject knowledge, pedagogical knowledge, subject knowledge and pedagogy, critical reflection/beliefs/orientation, standards alignment, skill/efficiency, teacher discourse/collaboration, and practice community." Furthermore, our experience attests that ASU's Teach English Now! possesses the seven characteristics of effective 
professional development as outlined by Darling-Hammond, Hyler, \& Gardner (2017): it is focuses on a specific content, it employs active learning by using theories pertinent to adult learning, it facilitates collaboration, it uses models and provides modelling of best teaching practices, it offers mentoring and support from the experts, it offers opportunities for feedback (both from the peers and the experts) and self-reflection, and it is of substantial duration. The experience that we had with ASU's Teach English Now!'s innovative course format, dynamic and professional instructors, and collaborative and supportive community of learners made our MOOC OTPD journey worthwhile and rewarding. Our experience suggests that there is a plethora of quality MOOCs that anybody from anywhere in the world can take in order to advance professionally. It also implicates MOOC designers to develop sound curriculum design (Chugh et al., 2017) aligned with international standards and industry requirements and to deploy highly competent virtual instructors (Mercado-Varela et al., 2017) whose effective e-mentoring skills (Tanis \& Barker, 2017) and excellent teaching skills may afford learners a worthwhile online distance education experience. Taking into account these considerations may be able to address the three current concerns with MOOCs as outlined by Soylev (2017): completion rates, pedagogy, and certification.

\section{CONCLUSION}

Teacher professional development is seen as a keystone in strengthening educators' performance levels and raising student achievement (Mizell, 2010). However, with increasing costs, lack of resources, and busy schedules, teachers are not always given opportunities to participate in TPDs; hence, there is a need for "online teacher professional development programs" (Whitehouse, Breit, McCloskey, Ketelhut, \& Dede, 2006) that will allow customized, self-paced, and expert-supported education. The concept of MOOCs for TPD appears to be a logical and practical answer to this concern. With the ubiquity of modern technologies, innovative MOOCs may prove to be a viable and practical means to afford teachers around the world the opportunity to develop and advance themselves professionally. Harnessing this emerging technology "may be a path to achieving a new educational order" (Mercado-Varela et al., 2017) and may revolutionize the way we view the teaching and learning processes. In this digital era when everything seems to be connected and accessible via the fingertips $24 / 7$, educational and training institutions can tap the technological resources to provide alternative TPD models, employing well-designed programs aligned with global standards, state-of-the-art approaches, expert virtual instructors, and strong technical support team. In the same vein, creators of MOOCs for TPD may need to incorporate latest research on MOOC users' experience into their course design to ensure higher success rate. The learners, on the other hand, must be cognizant of the many opportunities that abound, explore and take advantage of the modern means of professional development, and maximize their learning with eagerness, determination, and commitment. Furthermore, learners should possess digital competence, self-efficacy, self-management, and self-directed learning to be successful in this type of online education.

It is important to note some limitations of this study. First, this study reflects only the experiences of two MOOC participants in an eight-course specialization certificate for teacher professional development using Coursera MOOC platform. Hence, the findings in this study may limit their external validity to other MOOC participants' experiences, contexts, and settings. It would be interesting to explore MOOC participants' experiences across other MOOC platforms, types of MOOCs, and participants' level of education and digital competence. Furthermore, future studies may investigate MOOCs' utilization in a large group for teacher training, how MOOC camps can engage the participants and sustain their motivation in completing a course, and how MOOC participants integrate their learning from the MOOC into their pedagogical practices. 


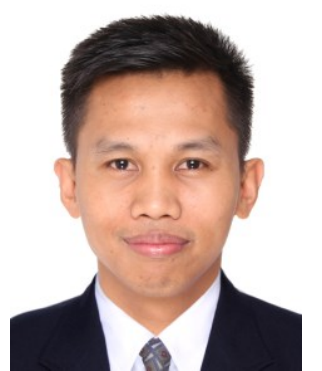

Romualdo A. MABUAN is an Assistant Professor of English at the College of Arts and Sciences, Lyceum of the Philippines University Manila, where he was awarded as the Most Outstanding Faculty Member for two consecutive years in 2015 and 2016. He holds a master's degree in teaching the English language and is a Doctor of Philosophy in Applied Linguistics candidate and a Commission on Higher Education scholar at De La Salle University, Manila. He holds a TESOL Certificate from Arizona State University, USA and is a TESOL Trainer at TESOL Asia. He is an E-Teacher Alumnus at the U.S. Department of State and is recognized by the Regional English Language Office at the U.S. Embassy - Manila as a Massive Open Online Course (MOOC) Camp Facilitator for various TESOL courses. His research interests include ICT in education, distance education, and teacher training.

Romualdo A. MABUAN

Department of English and Literature, College of Arts and Sciences

Address: Lyceum of the Philippines University, 1002, Manila, Philippines

Phone: +639087817058

E-mail: ra.mabuan@yahoo.com

\section{REFERENCES}

Bayne, S., \& Ross, J. (2014). The pedagogy of the Massive Open Online Course: the UK view, The Higher Education Academy (Series Ed.) Recuperado el, 30. Retrieved fromwww.heacademy.ac.uk/sites/default/files/hea_edinburgh_mooc_web_240 314_1.pdf

Billington, P. J., \& Fronmueller, M. P. (2013). MOOCs and the future of higher education. Journal of Higher Education Theory and Practice, 13(3), 3642. Retrieved from http://www.nabusinesspress.com/JHETP/BillingtonPJ_Web13_3_4_.pdf

Bochner, A., \& Ellis, C. (1995). Telling and living: Narrative coconstruction and the practices of interpersonal relationships. In Wendy Leeds Hurwitz (Ed.), Social approaches to communication (pp.201213). New York: Guilford.

Bordo, S. (1990). Feminism, postmodernism and gender skepticism. In L. Nicholson (Ed.), Feminism/postmodernism (pp. 133-156). New York, NY: Routledge.

Borko, H. (2004). Professional Development and Teacher Learning: Mapping the Terrain. Educational Researcher, 33(8), 3-15.

Bormann, G., Gamoran, A., \& Bowdon, J. (2008). A Randomized Trial of Teacher Development in

Elementary Science: First-Year Achievement Effects. Journal of Research on Educational Effectiveness, 1, 237-264.

Brabon, B. (2014). Talking about quality: Massive misalignment: the challenges of designing and accrediting MOOCs. Retrieved from www.qaa.ac.uk/en/Publications/Documents/Talkingabout-Quality-MOOCsBrabon.pdf 
Charmaz, K. (1983). The grounded theory method: An explication and interpretation. In Robert M. Emerson (Ed.), Contemporary field research: A collection of readings (pp.109125).Prospect Heights, IL: Waveland.

Chase, S. E. (2005). Narrative inquiry: Multiple lenses, approaches, voices. In Norman K. Denzin \& Yvonna S. Lincoln (Eds.), The handbook of qualitative research (3rd ed., pp.651-679). Thousand Oaks, Ca: Sage.

Chen, Y. (2014). Investigating MOOCs through Blog Mining. International Review of Research in Open and Distributed Learning, 15(2). Retrieved from http://www.irrodl.org/index.php/irrodl/article/view/1695/2884

Christensen, C. (2010). Disrupting class, expanded edition: How disruptive innovation will change the way the world learns. New York: McGraw-Hill.

Chugh, R., Ledger, S., \& Shields, R. (2017). Curriculum design for distance education in the tertiary sector. The Turkish Online Journal of Distance Education, 18(2), 415.

Clandinin, D. J., \& Connelly, F. M. (2000). Narrative inquiry: Experience and story in qualitative research. San Francisco: Jossey-Bass.

Clifford, J., \& Marcus, G. E. (1986). Writing culture: The poetics and politics of ethnography. Berkeley: University of California Press.

Connelly, F. M., \& Clandinin, D. J. (1990). Stories of experience and narrative inquiry. Educational Researcher, 19(5), 2-14.

Conole, G. (2013). MOOCs as disruptive technologies: strategies for enhancing the learner experience and quality of MOOCs. Revista de Educación a Distancia, 39, 1-17.

Creelman, A., Ehlers, U. D., \& Ossiannilsson, E. S. (2014). Perspectives on MOOC quality: An account of the EFQUEL MOOC Quality Project, INNOQUAL, International Journal for Innovation and Quality in Learning, 2(3).

Darling-Hammond, L., Hyler, M., \& Gardner, M. (2017). Effective Teacher Professional Development. Pato Alto, CA: Learning Policy Institute.

Decker, G. L. (2014). Moocology 1.0. In Krause, S., \& Lowe, C. (Eds), Invasion of the MOOCs: The promise and perils of massive open online courses (pp. 3-13). South Carolina: Parlor Press.

Denzin, N. K., Lincoln, Y. S., \& Smith, L. T. (Eds.) (2008). Handbook of critical and Indigenous methodologies. Thousand Oaks, CA: Sage.

Dyer, R. A. D. (2014). Exploring the relevancy of massive open online courses (MOOCs): A Caribbean university approach. Information Resources Management Journal, 27(2), 6177.

Educause. (2011). 7 Things You Should Know about MOOCs. Retrieved from https: //net.educause.edu/ir/library/pdf/eli7078.pdf

Ellis, C. (2004). The ethnographic I: A methodological novel about autoethnography. Walnut Creek, CA: AltaMira Press.

Emanuel, E. J. (2013). Online education: MOOCs taken by educated few. Nature, 503(7476), 342-342.

Evans, L. (2002). What is teacher development? Oxford Review of Education, 28(1), 123137. 
Hayes, S. (2015). MOOCs and Quality: A Review of the Recent Literature. The Quality Assurance Agency for Higher Education. Gloucester: Southgate House.

Heller, J. I., Dahler, K. R., Wong, N., Shinohara, M., \& Miratrix, L. W. (2012).Differential effects of three professional development models on teacher knowledgeand student achievement in elementary science. Journal of Research in ScienceTeaching, 49, 333-362.

Holman-Jones, S. (2005). Autoethnography: Making the personal political. In Norman K. Denzin \& Yvonna S. Lincoln (Eds.), Handbook of qualitative research (pp.763791). Thousand Oaks, CA: Sage.

Jobe, W., Ostlund, C. \& Svensson, L. (2014). MOOCs for Professional Teacher Development. In M. Searson \& M. Ochoa (Eds.), Proceedings of SITE 2014-Society for Information Technology \& Teacher Education International Conference (pp. 1580-1586). Jacksonville, Florida, United States: Association for the Advancement of Computing in Education (AACE). Retrieved from https: //www.learntechlib.org/p/130997/

Johnson, D. H. (2013). Teaching a "mooc:" Experiences from the front line. IEEE Digital Signal Processing and Signal Processing Education Meeting (DSP/SPE)(pp. 268272).

Kennedy, M. (2016). How Does Professional Development Improve Teaching? Review of Educational Research, 86(4), 945-980.

Kennedy, M. M. (1998). Form and substance in inservice teacher education. Madison:University of Wisconsin National Institute for Science Education. Retrieved fromhttps://www.msu.edu/ mkennedy/publications/valuePD.html

Kocdar, S., Okur, M. R., \& Bozkurt, A. (2017). An examination of XMOOCs: An embedded single case study based on Conole's 12 Dimensions. The Turkish Online Journal of Distance Education, 18(4), 52-65.

Lisa M. (1997). Interactive interviewing: Talking about emotional experience. In Rosanna Hertz (Ed.), Reflexivity and voice (pp.119149). Thousand Oaks, CA: Sage.

Liyanagunawardena, T. R., Adams, A. A., \& Williams, S. A. (2013). MOOCs : A systematic study of the published literature 20082012. The International Review of Research in Open and Distance Learning, 14(3), 202-227. Retrieved from http:// www.irrodl.org/index.php/irrodl/article/view/1455

Lowe, C. (2014). Introduction: Building on the Tradition of CCKO8 in Invasion of the MOOCs: Promises and Perils of Massive Open Online Courses. USA: Parlor Press.

Mackness, J., Waite, M., Roberts, G., \& Lovegrove, E. (2013). Learning in a small, taskoriented, connectivist MOOC: Pedagogical issues and implications for higher education. The International Review of Research in Open and Distance Learning, 14(4). Retrieved from http://www.irrodl.org/index.php/irrodl/article/view/1548/2687

Mercado-Varela, M. A., Beltran, J., Perez, M. V., Vasquez, N. R., Ramirez-Montoya, M. (2017). Connectivity in learning in MOOCs: Facilitators' experiences in team teaching. The Turkish Online Journal of Distance Education, 18(1), 143-156.

Mizell, H. (2010). Why professional development matters. Oxford, OH: Learning Forward. 
Odden, A., Archibald, S., Fermanich, M., \& Gallagher, H. A. (2002). A Cost Framework for Professional Development. Journal of Education Finance, 28(1), 51-74. Retrieved from http://www.jstor.org/stable/40704157

Opfer, D., \& Pedder, D. (2011). Conceptualizing teacher professional learning. Reviewof Educational Research, 81, 376-407. doi:10.3102/0034654311413609

Pappano, L. (2012). The year of the MOOC. The New York Times, 2(12).

Penuel, W. R., Gallagher, L. P., \& Moorthy, S. (2011). Preparing teachers to designsequences of instruction in earth science: A comparison of three professional developmentprograms. American Educational Research Journal, 48, 996-1025. doi:10.3102/0002831211410864

Philippine Institute for Development Studies (2015). Massive Open Online Courses: A Primer for Philippine State Universities and Colleges, Quezon City, Philippines: Philippine Institute for Development Studies.

Pope, J. (2013). Coursera To Offer MOOC Options Targeting Teacher Education. Community College Week, 25(21), 10-10.

Rosaldo, R. (1989). Culture and Truth: The Remaking of Social Analysis. Boston, MA: Beacon Press.

Roschelle, J., Shechtman, N., Tatar, D., Hegedus, S., Hopkins, B., Empson, S., Gallagher, L. P. (2010). Integration of technology, curriculum, and professional development for advancing middle school mathematics: Three large-scale studies. American Educational Research Journal, 47, 833-878. doi:10.3102/0002831210367426

Roth, K. J., Garnier, H. E., Chen, C., Lemmens, M., Schwille, K., \& Wickler, N. I. Z. (2011).Video-based lesson analysis: Effective science PD for teacher and student learning. Journal for Research in Science Teaching, 48, 117-148. doi:10.1002/tea.20408

Schon, D. A. (1987a). Educating the reflective practitioner. Washington, D. C.: American Educational Research Association.

Sher, L., \& O'Reilly, F. E. (2009). Professional development for K-12 math and scienceteachers: What do we really know? Journal of Research on Educational Effectiveness, 2, 209-249. doi: 10.1080/19345740802641527

Soylev, A. (2017). MOOCs 2.0: The social era of education. The Turkish Online Journal of Distance Education, 18(2), 56-67.

Stenhouse, L. (Ed.) (1975). An Introduction to Curriculum Research and DevelopmentLondon: Heinemann.

Suleiman, S. (1986). The Female Body in Western Culture: Contemporary Perspectives. Cambridge, MA: Harvard University Press.

Tanis, H., \& Barker, I. (2017). E-mentoring at a distance: An approach to support professional development in workplaces. The Turkish Online Journal of Distance Education, 18(3), 135-155.

Tedlock, B. (1991). From participant observation to the observation of participation: The emergence of narrative ethnography. Journal of Anthropological Research, $47(1), 6994$.

The Quality Assurance Agency for Higher Education. (2014). Statement on Massive Open Online Courses. Retrieved from www.qaa.ac.uk/en/Publications/ Documents/QAA-position-statement-MOOCs.pdf 
Thrun, S. (2012, January 23). Higher education 2.0 [Video file]. Retrieved from www.youtube.com/watch?feature=player_embedded $\& v=S k n e o N r f a d k$

Tillmann, L. M. (2009). Body and bulimia revisited: Reflections on "A Secret Life." Journal of Applied Communication Research, 3X(1), 98112.

Toyosaki, S., \& Pensoneau, S. (2005). Yaezakura-Interpersonal culture analysis. International Journal of Communication, 15(12), 5188.

Toyosaki, S., Pensoneau, S., Wendt, N., \& Leathers, K. (2009). Community autoethnography: Compiling the personal and resituating whiteness. Cultural Studies $\leftrightarrow$ Critical Methodologies, 9(1), 5683.

Turner, V., \& Bruner, E. M. (1986). The Anthropology of Experience. Urbana \& Chicago: University of Illinois.

Vande Berg, L., \& Trujillo, N. (2008). Cancer and death: A love story in two voices. Cresskill, NJ: Hampton Press.

Whitehouse, P., Breit, L., McCloskey, E., Ketelhut, D., \& Dede, C. (2006). An overview of current findings from empirical research on online teacher professional development. In Online professional development for teachers; Emerging models and methods, ed. C. Dede, 13-29. Cambridge, MA: Harvard University Press.

Wintrup, J., Wakefield., K, Morris, D., \& Davis, H. (2015). Liberating learning: experiences of MOOCs. Retrieved from http://eprints.soton.ac.uk/373639/1/HEA_liberatinglearning.pdf

Zancanaro, A., Nunes, C. S., \& Domingues, M. J. C. D. (2017). Evaluation of free platforms for delivery of Massive Open Online Courses (MOOCs). The Turkish Online Journal of Distance Education, 18(1), 166-181. 